\title{
Sustentabilidade no setor público brasileiro e nas instituições públicas de ensino superior: análise da produção científica em periódicos nacionais
}

O objetivo desse estudo é analisar o desenvolvimento e identificar as principais características de pesquisas acerca da sustentabilidade no setor público brasileiro e nas instituições públicas de ensino superior. Foi realizado um estudo descritivo, de abordagem quantitativa, utilizando-se de bibliometria mediante a seleção de artigos que tratam sobre o tema no portal de periódicos da Capes, no período de Janeiro de 2010 até Setembro de 2019, contendo em qualquer parte do texto as palavras exatas: sustentabilidade e administração pública; sustentabilidade e setor público; sustentabilidade e organizaç̃̃es públicas; sustentabilidade e instituição pública; sustentabilidade e instituição federal; sustentabilidade e instituição estadual; sustentabilidade e instituição municipal; sustentabilidade e instituição de ensino público; sustentabilidade e instituição de ensino pública; sustentabilidade e universidade pública. Dentre os principais resultados encontrados, destacam-se os seguintes: as instituições mais analisadas nos artigos foram as de ensino superior públicas, sustentando participação na metade do portfólio bibliográfico encontrados, destacam-se os seguintes: as instituições mais analisadas nos artigos foram as de ensino superior públicas, sustentando participação na metade do porttólio bibliográfico
selecionado; o tema avaliação e desenvolvimento da consciência sustentável foi o mais abordado; o ano de 2019 tende a registrar um número abaixo da média anual de publicações do período; a maioria dos artigos foram desenvolvidos em quartetos; os periódicos com maior número de publicações foram de Qualis B2, sendo a Revista de Gestão Ambiental e da Sustentabilidade a possuidora do maior acervo, e a instituição com maior número de publicações a Universidade Federal de Santa Catarina (UFSC).

\section{Sustainability in the Brazilian public sector and state run institutions of higher education: analysis of scientific production in national journals}

This study intends to analyze the development and identify the main characteristics of research works on sustainability in the Brazilian public sector and in public institutions of higher education. The quantitative approach was applied to perform descriptive study, using bibliometrics through the selection of articles that adressed the issue on Capes journals portal, from January 2010 to September 2019, which ones should contain any part of the text that corresponded to the exact words (either the female noun and male noun related to the term public in Portuguese): sustainability and public administration; sustainability and the public sector; sustainability and public organizations; sustainability and public institution; sustainability and federal institution: sustainability and state institution; sustainability and municipal institution; sustainability and public education institution; sustainability and public education institution; sustainability and public university. Among the main rults found, the following ones standed out: the institutions most analyzed in the articles were those of public higher education, which register a number below the largest number of publications were Qualis B2, with the Revista de Gestão Ambiental e da Sustentabilidade having the largest collection, and the institution with the largest number of publications being the Federal University of Santa Catarina (UFSC)

Keywords: Sustainability; Brazilian Public Sector; Public higher education institutions.

Topic: Gestão Pública

Reviewed anonymously in the process of blind peer
Received: 08/06/2020

Approved: $\mathbf{3 0 / 0 7 / 2 0 2 0}$
Maucir Marcuz Junior (id

Universidade Tecnológica Federal do Paraná, Brasil http://lattes.cnpq.br/0012087708377585

http://orcid.org/0000-0002-3093-7377

mmjunior@utfpr.edu.br

\section{Rogério Sauberlich (iD}

Universidade Tecnológica Federal do Paraná, Brasil

http://lattes.cnpq.br/6411280617669683

http://orcid.org/0000-0003-2590-1342

rsauberlich@utfpr.edu.br

Laís de Andrade Farias (iD

Universidade Tecnológica Federal do Paraná, Brasil

http://lattes.cnpq.br/3548590896553828

http://orcid.org/0000-0001-9011-5095

laisfarias@utfpr.edu.br

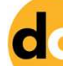

DOI: $10.6008 / C B P C 2179-684 X .2020 .003 .0013$
Daniel Poletto Tesser (iD

Universidade Tecnológica Federal do Paraná, Brasil

http://lattes.cnpq.br/874956790522814

http://orcid.org/0000-0003-3363-0984

danieltesser@utfpr.edu.br
Referencing this:

MARCUZ JUNIOR, M.; SAUBERLICH, R.; FARIAS, L. A.; TESSER, D. P.. Sustentabilidade no setor público brasileiro e nas instituições públicas de ensino superior: análise da produção científica em periódicos nacionais. Revista Brasileira de Administração Científica, v.11, n.3, p.183-198, 2020. DOI: http://doi.org/10.6008/CBPC2179$\underline{684 X .2020 .003 .0013}$ 


\section{INTRODUÇÃO}

Diversos problemas econômicos, sociais e ecológicos têm sido apresentados como consequência do atual modelo de desenvolvimento. A degradação do meio ambiente, o desgaste dos solos, a poluição do ar e da água são exemplos de como o homem coloca em perigo seu próprio habitat, contrariando os princípios fundamentais da sustentabilidade (ROOS et al., 2012).

Envolto nessa realidade, o setor público por meio de suas instituições, atua na produção, entrega e distribuição de bens e serviços para os cidadãos. Através de uma administração direta a União, Estados, Distrito Federal e Municípios, prestam serviços públicos por seus próprios meios e através de uma administração indireta delega essa função para autarquias, fundações, sociedades de economia mista ou empresas públicas, possuidoras de personalidade jurídica própria, patrimônio e autonomia administrativa. Estão presentes nessa grande estrutura uma variedade de instituições com diversos objetivos. Dentre essas, merecem destaque as instituições públicas de ensino superior, que perfazem o total de 299 no Brasil (INEP, 2019).

Em geral, somente as instituições públicas vinculadas à esfera ambiental são lembradas quando se verifica a atuação do setor público nessa perspectiva. Embora tenha sido concebida em 1999 a Agenda Ambiental na Administração Pública (A3P), e desde 2012 esteja estabelecida a elaboração e implementação dos Planos de Gestão de Logística Sustentável, além de outras ações governamentais que buscam o desenvolvimento sustentável, via de regra, nota-se uma dissonância entre os órgãos afins à temática ambiental e todos os demais integrantes da Administração Pública, onde a pauta ambiental não tem exercido a mesma relevância diante de outras, como a promoção da accountability. Contudo, a adequação no trato da utilização dos estoques de recursos naturais, a redução de custos e desperdícios não se constituem em meras ações cujas finalidades sejam exclusivamente a proteção ao meio ambiente, elas são também fundamentos do princípio da eficiência, norteador da conduta do servidor público. Assim, se espera do setor e servidor público a aplicação de práticas de sustentabilidade (CHELALA, 2012).

Esse anseio também atinge as instituições públicas de ensino, onde se espera que a sensibilização e conscientização da comunidade acadêmica e a inserção das questões ambientais no processo educativo, resultem em participações em projetos, congressos, cursos de extensão e ações praticadas em suas estruturas (SANTOS, 2018).

Desse modo, é necessário que a sociedade tenha ciência das propostas e ações desenvolvidas no tocante à sustentabilidade por todos os órgãos do setor público. Tendo em vista que a publicação de artigos científicos é uma das ferramentas de transmissão desse conhecimento, foram desenvolvidos alguns trabalhos relevantes nessa conjuntura.

Chaves et al. (2013) analisaram a construção do conhecimento sobre o tema gestão socioambiental em instituições de ensino no período de 2002 a meados de 2012 nas bases internacionais ISIKNOWLEDGE, SCOPUS e EBSCO, acessíveis pelo Portal de Periódicos da CAPES. Utilizaram-se do método ProKnow-C para seleção do portfólio bibliográfico e análise bibliométrica, onde foram selecionados 14 artigos de 
reconhecimento científico e como resultado identificaram os autores, periódicos, palavras chaves e os artigos mais reconhecidos.

Rubbo et al. (2016) analisaram a produção científica internacional acerca da sustentabilidade organizacional, no período de 2005 a 2014, na base de dados Scopus. Os autores selecionaram 21 artigos e constataram que, predominantemente, os artigos publicados são redigidos em inglês, escrito por dois autores e o país com mais concentração de autores é os Estados Unidos da América.

Henchen et al. (2019) analisaram a evolução das publicações científicas acerca do tema gestão socioambiental e sustentabilidade, na prática das Instituições de Ensino Superior (IES), no período de 01/01/2002 até 01/03/2017, na base de dados SCOPUS. Utilizaram-se do método ProKnow-C para seleção do portfólio bibliográfico e análise bibliométrica, onde foram selecionados 40 artigos e como resultado identificaram os autores, periódicos, palavras chaves e os artigos mais reconhecidos, sendo observado um incremento significativo no número de citações dos artigos do portfólio bibliográfico nos últimos cinco anos da análise.

Rohrich et al. (2019) investigaram o perfil das pesquisas sobre o tema sustentabilidade ambiental em instituições de ensino nos artigos publicados em periódicos nacionais no período de 2006 a 2015, através de busca nos periódicos associados ao ENGEMA (Encontro Internacional de Gestão Empresarial e Meio Ambiente) e no site de periódicos da CAPES. Foi constatado que a evolução do aprendizado acadêmico obtido pela experiência dos pesquisadores vem trazendo um amadurecimento nos trabalhos, que já apresentam um histórico de pesquisas, conceitos e resultados que estão sendo agregados ao longo do tempo, construindose assim o conhecimento na área.

Nesse contexto, o diferencial desse artigo é o enfoque dado ao setor público brasileiro e as instituições públicas de ensino, levando em consideração as publicações de periódicos nacionais no período de Janeiro de 2010 a Setembro de 2019, tendo como objetivo analisar o desenvolvimento de pesquisas acerca dessa matéria de grande relevância, identificando as principais características dos trabalhos elaborados. Ao focar essa temática o artigo estimula a reflexão sobre o tema e soma esforços à literatura acerca da sustentabilidade.

A estrutura deste trabalho é sistematizada por cinco seções, começando com esta introdução; a próxima seção aborda o referencial teórico; na sequência será explicada a metodologia adotada, com a descrição dos procedimentos técnicos adotados para a coleta de dados, a amostra e os procedimentos de análise; posteriormente serão apresentadas as análises dos resultados encontrados; por fim, as considerações finais.

\section{REVISÃO TEÓRICA}

\section{Sustentabilidade no Setor Público}

De acordo com o art. 225 da Constituição Federal (1988): "Todos têm direito ao meio ambiente ecologicamente equilibrado, bem de uso comum do povo e essencial à sadia qualidade de vida, impondo-se 
ao poder público e à coletividade o dever de defendê-lo e preservá-lo para as presentes e futuras gerações". Mais do que uma obrigação legal, "o poder público tem papel fundamental não somente de fomento de um mercado inovador e mais sustentável, mas também de educação, mobilização e conscientização da sociedade de um modo geral" (BETIOL et al., 2012).

A Administração Pública encontra prerrogativa para promoção de práticas sustentáveis em face ao seu poder de promulgação de leis, normas e regulamentos. Devido a sua grande capacidade em comprar e consumir, também possui grande potencial para atuar como reguladora fática de mercado (ROCHA et al., 2016). Não obstante a esse cenário, os gestores públicos devem assumir uma postura ativa, de comprometimento social e ambiental, em busca do desenvolvimento sustentável (CHAVES et al., 2013). “É preciso que as pessoas que fazem a gestão pública desenvolvam o princípio da economicidade e eficiência, uma vez que a administração pública é uma grande consumidora/usuária dos recursos naturais" (CAMELO et al., 2015).

Com essa justificativa, a A3P foi concebida no final de 1999, pelo Ministério do Meio Ambiente e oficializada pela Portaria № 510/2002. Trata-se de um programa governamental que visa promover a inserção de princípios e práticas de sustentabilidade socioambiental, no âmbito da administração pública, que tem como objetivo estimular a reflexão e mudança de atitude dos servidores e gestores, promover a economia de recursos naturais e redução de gastos institucionais, reduzir o impacto socioambiental negativo causado pela execução das atividades de caráter administrativo e operacional, contribuir para melhoria da qualidade de vida, revisão dos padrões de produção e consumo e na adoção de novos referenciais, no âmbito da administração pública. Essa ferramenta está estruturada a partir de seis eixos temáticos prioritários: I) Uso racional dos recursos naturais e bens públicos; II) Gestão adequada dos resíduos gerados; III) Qualidade de vida no ambiente de trabalho; IV) Sensibilização e capacitação dos servidores; V) Licitações sustentáveis e VI) Construções sustentáveis (BRASIL, 2016).

A implantação da A3P pode ser realizada em toda a administração pública, sem exceções. Muitas organizações e instituições governamentais ou não governamentais têm construído agendas ambientais e agendas 21, tomando esse programa como modelo de gestão socioambiental (CAVALCANTE, 2012). A Tabela 1 apresenta um panorama acerca das instituições públicas que possuem termo de adesão ao programa vigente na data de 30 de Setembro de 2019.

Tabela 1: Composição dos órgãos adeptos a A3P.

\begin{tabular}{lll}
\hline Poder & No de Instituições & Percentual \\
\hline Executivo & 159 & $75,71 \%$ \\
Legislativo & 17 & $8,10 \%$ \\
Judiciário & 25 & $11,90 \%$ \\
Independente & 9 & $4,29 \%$ \\
\hline
\end{tabular}

Fonte: Brasil (2019).

Outra iniciativa promovida pela administração pública em busca das práticas de sustentabilidade foi a instituição dos Planos de Logística Sustentável (PLS) criados pelo art. 16, do Decreto no 7.746, de 05 de junho de 2012, da Presidência da República do Brasil e institucionalizado por meio da Instrução Normativa 
no 10, de 12/11/2012, do Ministério do Planejamento, Orçamento e Gestão, onde apresenta em seu art. 11, § III, a A3P como uma das iniciativas referenciais para elaboração dos planos. O PLS deve ser desenvolvido e implementado por todos os órgãos e entidades da Administração Pública federal direta, autárquica, fundacional e as empresas estatais dependentes e nele deve estar contido conteúdos e temas mínimos, conforme apresentado na Figura 1. Os sete temas mínimos a serem desenvolvidos para cada PLS, estão dispostos no artigo 8o da Instrução Normativa no 10, de 12/11/2012. Já os conteúdos mínimos para elaboração do PLS, estão elencados no Decreto no 7.746/2012, Art. 16, I-IV.



Figura 1: Conteúdos e temas mínimos exigidos no PLS. Fonte: Com base na IN. 10/2012-MPOG e Decreto no $7.746 / 2012$.

Em especial, na administração pública federal, o Tribunal de Contas da União (TCU) criou um importante instrumento para avaliação das ações de sustentabilidade a serem implementadas pelas instituições públicas a ele vinculadas. O Índice de Acompanhamento da Sustentabilidade na Administração (IASA) foi concebido para que ocorra o acompanhamento, mensuração e evolução dessas medidas. Dessa maneira, além de exercer sua função fiscalizadora, o tribunal tem desempenhado um trabalho relevante, estimulando os órgãos a adotarem práticas de sustentabilidade e responsabilidade social, tendo em vista que a inserção dos valores da sustentabilidade na Administração fomenta a transparência nos gastos públicos e ganho de eficiência. O índice foi definido como a média de onze critérios/eixos temáticos, conforme apresentado no Quadro 1 e possui uma escala de avaliação que varia de 0 a 3, sendo dividido em três faixas, onde se considera inferior a faixa de desempenho de 0 a 1, intermediária de 1 a 2 e superior de 2 a 3 (TCU, 2017).

Quadro 1: Eixos Temáticos do IASA.

\begin{tabular}{|l|l|}
\hline No & Eixo Temático \\
\hline 1 & Elaboração, implementação e monitoramento do PLS \\
\hline 2 & Racionalização no uso de energia elétrica \\
\hline 3 & Racionalização no uso de água \\
\hline 4 & Atendimento a requisitos de acessibilidade \\
\hline 5 & Certificação de prédios públicos \\
\hline 6 & Racionalização no uso de papel e implementação de processo eletrônico \\
\hline 7 & Gestão de resíduos e coleta seletiva \\
\hline 8 & Contratações públicas sustentáveis \\
\hline 9 & Mobilidade e gases de efeito estufa \\
\hline 10 & Conscientização e capacitação \\
\hline 11 & Adesão a programas de sustentabilidade \\
\hline
\end{tabular}

Fonte: TCU (2017). 
A administração pública federal obteve uma pontuação média de 1,64 (Figura 2), enquadrando-se na faixa intermediária, o que representa que há muito para ser melhorado no tocante a sustentabilidade.

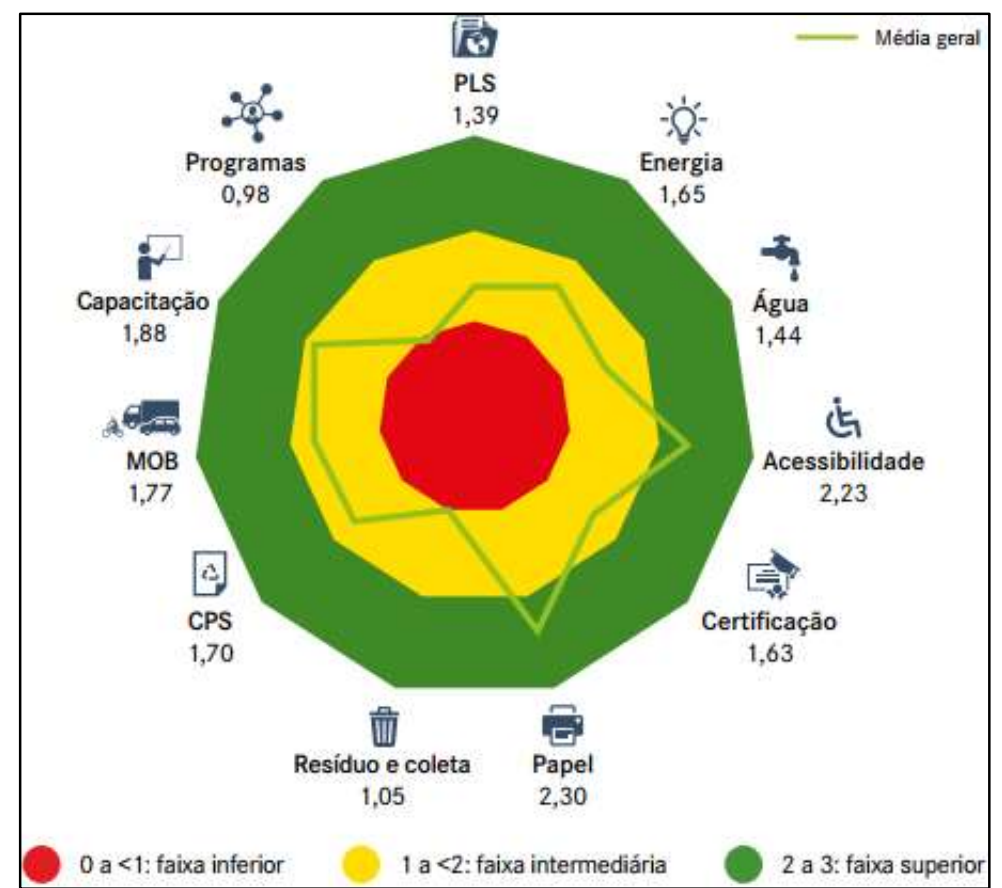

Figura 2: IASA referente à administração pública federal. Fonte: TCU (2017).

Além das ações governamentais já citadas acima, merecem destaque também as seguintes: Coleta Seletiva Solidária, que determina a separação dos resíduos recicláveis descartados pelas instituições da administração pública federal, e a sua destinação às associações e cooperativas dos catadores de materiais recicláveis (BRASIL, 2006); Programa Nacional de Conservação de Energia Elétrica (PROCEL), que promove ações de eficiência energética em diversos segmentos da economia e sociedade; Contratações Públicas Sustentáveis (eixo temático da A3P e IASA, tema mínimo requisitado no PLS), que através do poder de compra do Estado congrega critérios de sustentabilidade em todas as etapas de contratações, visando à proteção ao meio ambiente e o desenvolvimento econômico e social; Programa de Eficiência do Gasto Público (PEG), que estimula o intercâmbio de boas práticas de gestão entre órgãos e entidades públicas, onde através de um sistema os participantes coletam dados para o planejamento, definem metas de gasto e elaboram planos de ações, para posterior acompanhamento e controle; Projeto Esplanada Sustentável (PES), cuja finalidade é integrar ações que visam à melhoria da eficiência no uso racional dos recursos públicos e à inserção da variável socioambiental no ambiente de trabalho, como a A3P, PROCEL, PEG e Coleta Seletiva Solidária (MPOG, 2012).

\section{Sustentabilidade nas instituições públicas de ensino superior}

Em Setembro de 2015 chefes de Estado e de Governo e altos representantes, reunidos na sede das Nações Unidas em Nova York firmaram um dos maiores acordos globais da história recente. Um plano de ação voltado para as pessoas, para o planeta e para a prosperidade, composto de 17 Objetivos de Desenvolvimento Sustentável (ODS) e 169 metas, compiladas em um documento denominado 
'Transformando nosso mundo: a Agenda 2030 para o Desenvolvimento Sustentável'. Vigente desde Janeiro de 2016, a agenda aborda os desafios mundiais de maior urgência: acabar com a pobreza, aumentar a prosperidade econômica, a inclusão social, a sustentabilidade ambiental, a paz e o bom governo para todos os povos até 2030 (ONU, 2015).

Dentro desse contexto, se faz necessário e de grande importância a participação efetiva das instituições públicas de ensino superior brasileiras, pois o Brasil é um dos países signatários desse acordo. É fundamental que essas instituições conduzam o processo de implementação dos ODS, pois com a ausência desse engajamento é provável que nenhum dos 17 objetivos possam ser cumpridos. Para esse segmento, trata-se de uma oportunidade de reafirmar sua relevância e comprometimento perante a sociedade, de estimular o interesse de formação relacionada aos ODS, de obtenção de novas fontes de financiamento, com base em parcerias realizadas (SDSN, 2017).

Nesse sentido, com o objetivo de promover a cultura de desenvolvimento sustentável, contribuir para formação de uma geração comprometida e desenvolver uma agenda acadêmica, foi criado em junho de 2017 a Rede ODS Universidades Brasil, à qual os participantes terão acesso a um banco de dados e um canal de comunicação para troca de informações referentes a ações e inovações de ensino, pesquisa e extensão convergentes com os objetivos de desenvolvimento sustentável.

As IES têm como missão e dever originar a formação de profissionais conscientes da importância das práticas de sustentabilidade e da preservação do meio ambiente. Assim, devem adotar metodologias que estimulem a sensibilização e a conscientização de sua comunidade acadêmica, partindo da teoria para adoção de ações práticas, promovendo o engajamento de seus servidores, docentes e discentes (SANTOS, 2018). Inseridas dentro da administração pública, as instituições públicas de ensino superior podem e devem aderir aos programas já citados na subseção anterior. O Quadro 2 apresenta as instituições públicas de ensino superior que possuem termo de adesão ao programa vigente na data de 30 de Setembro de 2019.

Quadro 2: Instituições de ensino superior com adesão vigente ao programa A3P.

\begin{tabular}{|l|l|}
\hline № & Instituições \\
\hline 1 & Instituto Federal de Educação, Ciência e Tecnologia Catarinense (Campus Brusque) \\
\hline 2 & Instituto Federal de Educação, Ciência e Tecnologia de Brasília - IFB \\
\hline 3 & Instituto Federal de Educação, Ciência e Tecnologia de Santa Catarina - IFSC \\
\hline 4 & Instituto Federal de Educação, Ciência e Tecnologia do Acre - IFAC \\
\hline 5 & Instituto Federal de Educação, Ciência e Tecnologia do Amazonas - IFAM \\
\hline 6 & Instituto Federal de Educação, Ciência e Tecnologia do Espírito Santo (Campus Guarapari) \\
\hline 7 & Instituto Federal de Educação, Ciência e Tecnologia do Piauí (Campus Corrente) \\
\hline 8 & Instituto Federal de Educação, Ciência e Tecnologia do Piauí (Campus Floriano) \\
\hline 9 & Instituto Federal de Educação, Ciência e Tecnologia do Rio de Janeiro - IFRJ \\
\hline 10 & Universidade Estadual do Maranhão \\
\hline 11 & Universidade Estadual do Rio Grande do Norte \\
\hline 12 & Universidade Federal de Grande Dourados \\
\hline 13 & Universidade Federal de Pernambuco \\
\hline 14 & Universidade Federal de Pernambuco (Campus do Agreste) \\
\hline 15 & Universidade Federal de Santa Maria (Campus Palmeira das Missões) \\
\hline 16 & Universidade Federal de Sergipe \\
\hline 17 & Universidade Federal de Uberlândia \\
\hline 18 & Universidade Federal do Rio Grande \\
\hline
\end{tabular}

Fonte: Brasil (2019).

Servir de exemplo para sua comunidade e para sociedade, atender a legislação, tratar de forma 
transparente e íntegra as questões socioambientais é um dever dessas instituições. Dispor de uma agenda integrada de ensino e pesquisa multidisciplinar, que considere os desafios e as necessidades do governo e da sociedade é de grande significância para o fomento de uma economia sustentável (PINSKY et al., 2019).

\section{METODOLOGIA}

Realizou-se uma busca avançada por assunto no portal de periódicos da Capes no dia 09/10/2019 com todas as bases de dados e idiomas disponíveis, na qual foram identificados os artigos publicados no período de Janeiro de 2010 a Setembro de 2019, contendo em qualquer parte do texto as palavras exatas: sustentabilidade e administração pública; sustentabilidade e setor público; sustentabilidade e organizações públicas; sustentabilidade e instituição pública; sustentabilidade e instituição federal; sustentabilidade e instituição estadual; sustentabilidade e instituição municipal; sustentabilidade e instituição de ensino público; sustentabilidade e instituição de ensino pública; sustentabilidade e universidade pública. Para cada termo pesquisado, obtiveram-se os resultados encontrados. Na sequência, processou-se uma seleção inicial dos artigos mediante leitura de seus resumos, no qual foram excluídos os que não possuíam relação com o tema e os publicados em periódicos de origem internacional, após confirmação da nacionalidade no site da revista. Já os artigos que possuíam relação com o tema e que foram publicados em periódicos de origem nacional, foram classificados para uma nova triagem e importados para uma planilha de dados, sendo distribuídos por ano da publicação, título, revista, classificação Qualis-Periódicos, autores, sexo dos autores, instituição, titulação, objetivos da pesquisa, abordagem, procedimento e tema.

Por fim, aplicou-se uma seleção final dos artigos com o intuito de evitar a duplicidade, pois alguns desses foram localizados em mais de um termo de busca. Após essa nova apuração foi possível alcançar a amostra composta pelos artigos que serão objeto de análise. A Figura 3 apresenta um fluxograma do método realizado para seleção dos dados.

Para agrupar os artigos de acordo com o Qualis-Periódicos, foi considerada a classificação do quadriênio 2013-2016, na área de avaliação: Administração Pública e de Empresas, Ciências Contábeis e Turismo ou Interdisciplinar, na respectiva ordem de preferência. Foram classificadas em uma categoria específica (N/A) as revistas que não foram avaliadas no período ou não se enquadravam em nenhuma das áreas de avaliação. Com relação à titulação dos autores, essa foi obtida de acordo com o informado nas publicações. Para os casos em que não havia essa informação, foi procedida a consulta de currículo na Plataforma Lattes, sendo considerada a titulação na data de publicação do artigo.

Os artigos foram classificados por temas por meio de uma adaptação dos eixos temáticos do IASA e da A3P, conforme detalhado no Quadro 3. No tocante ao enquadramento metodológico dos artigos analisados foram observados os quesitos objetivos e abordagem, sendo consideradas as definições apresentadas nesses, e para os casos que não houve menção, procedeu-se a classificação conforme definições de Farias Filho et al. (2015). 


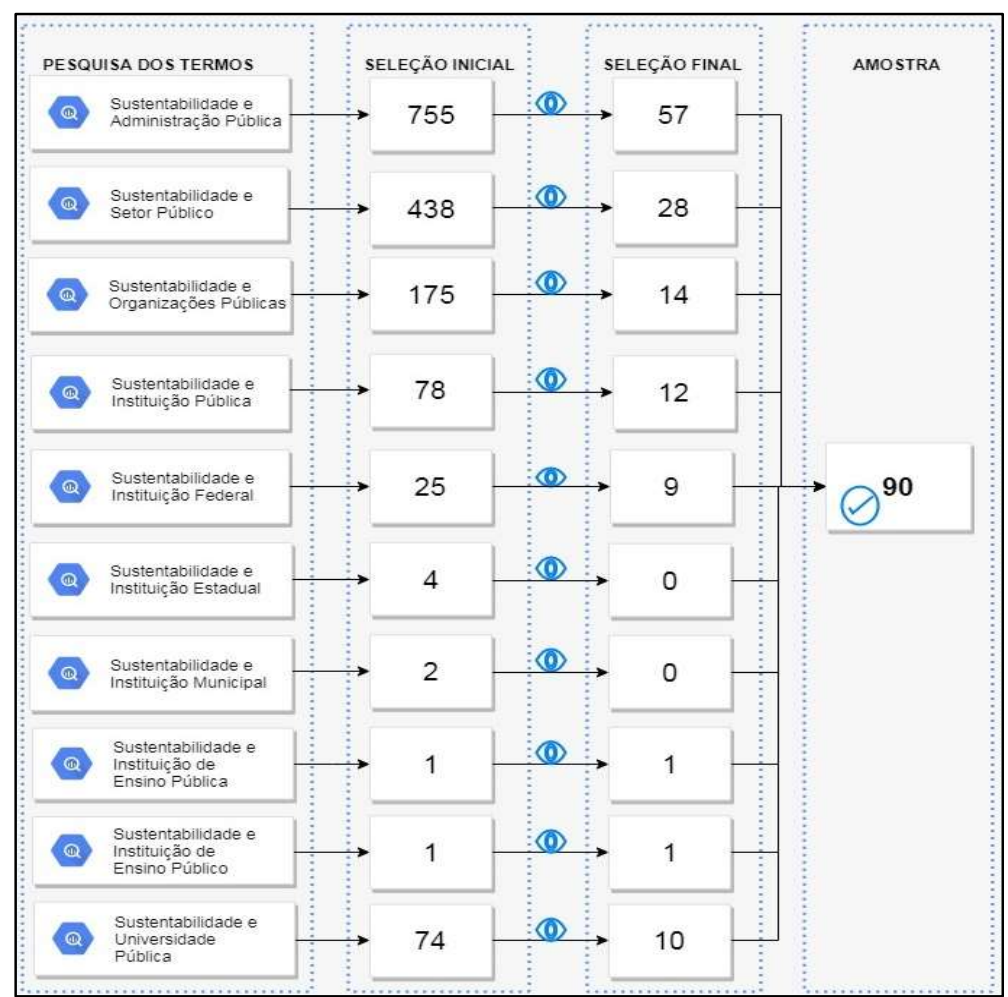

Figura 3: Fluxograma do procedimento de coleta de dados.

Quadro 3: Detalhamento da classificação dos artigos por temas.

\begin{tabular}{|l|l|}
\hline \multicolumn{1}{|c|}{ Tema } & \multicolumn{1}{c|}{ Descrição } \\
\hline $\begin{array}{l}\text { Avaliação e } \\
\text { Desenvolvimento da } \\
\text { Consciência Sustentável }\end{array}$ & $\begin{array}{l}\text { Medição do grau de sustentabilidade da instituição/Campanhas de educação ambiental e de práticas } \\
\text { sustentáveis /Elaboração, implementação e monitoramento do PLS/ Estudo sobre o desenvolvimento } \\
\text { de pesquisas acerca da sustentabilidade }\end{array}$ \\
\hline $\begin{array}{l}\text { Compras Públicas } \\
\text { Sustentáveis }\end{array}$ & $\begin{array}{l}\text { Análise e avaliação da Licitação sustentável, também conhecida como ecoaquisição, compras verdes, } \\
\text { licitação positiva ou compra ambientalmente amigável }\end{array}$ \\
\hline $\begin{array}{l}\text { Gestão de Resíduos e } \\
\text { Coleta Seletiva }\end{array}$ & $\begin{array}{l}\text { Ferramentas e propostas para redução da geração de resíduos, aumento da reciclagem, reutilização } \\
\text { dos resíduos sólidos e destinação adequada dos rejeitos }\end{array}$ \\
\hline $\begin{array}{l}\text { Adesão a programas de } \\
\text { sustentabilidade }\end{array}$ & $\begin{array}{l}\text { A3P, ODS, Coleta Seletiva Solidária, PROCEL, PEG, PES, Desenvolvimento de Projetos de Extensão } \\
\text { Próprios, entre outros. }\end{array}$ \\
\hline Eficiência Energética & $\begin{array}{l}\text { Desenvolvimento de ferramentas e avalição do consumo eficiente, padronização de equipamentos, } \\
\text { substituição de lâmpadas, alternativas para climatização }\end{array}$ \\
\hline $\begin{array}{l}\text { Racionalização no uso } \\
\text { da água }\end{array}$ & $\begin{array}{l}\text { Estudos e execução de projetos de reuso e de aproveitamento da água e programas de uso racional da } \\
\text { água }\end{array}$ \\
\hline $\begin{array}{l}\text { Racionalização no uso } \\
\text { do papel }\end{array}$ & Estudos e execução de projetos que visam economia de papel \\
\hline $\begin{array}{l}\text { Construçães } \\
\text { Sustentáveis }\end{array}$ & $\begin{array}{l}\text { Alternativas de construções visando a redução de impactos ambientais e aproveitamento de eficiência } \\
\text { máxima dos recursos naturais/Atendimento a requisitos de acessibilidade/ Certificação de prédios } \\
\text { públicos }\end{array}$ \\
\hline $\begin{array}{l}\text { Deslocamento de } \\
\text { Pessoal }\end{array}$ & Alternativas para diminuição da frota de automóveis visando à redução de gases de efeito estufa \\
\hline
\end{tabular}

Quanto à classificação metodológica dessa pesquisa, essa pode ser considerada como descritiva quanto a seus objetivos e de abordagem quantitativa, pois objetiva descrever as características de determinada população ou fenômeno, utilizando-se de técnicas estatísticas para a classificação e tradução das informações (FARIAS FILHO et al., 2015).

\section{RESULTADOS E DISCUSSÃO}

Inicialmente pode-se observar na Figura 4 que dos 90 artigos analisados, metade foi desenvolvida em observação às instituições públicas de ensino superior. Já a outra parcela, focalizou nas demais instituições do serviço público, esfera ou poder. Nesse contexto, é atestada a relevância das instituições 
públicas de ensino superior para a promoção da sustentabilidade, vide o grande interesse do desenvolvimento de estudos aplicados nessas instituições em relação às demais.



Figura 4: Distribuição dos artigos de acordo com as instituições/entidades do setor público.

A respeito da distribuição da publicação dos artigos por ano, verifica-se na Figura 5 que os anos de 2017 e 2018 atingiram o ápice, registrando cada um deles 18,88\% das publicações de todo período analisado. Ainda que o levantamento referente ao ano de 2019 corresponda apenas às publicações até 30 de Setembro, a tendência é que esse ano registre um número pequeno de publicações, abaixo da média anual de artigos publicados no período (9), assim como ocorreu no intervalo de 2010 a 2013. Nota-se que no ano de 2014 as publicações estiveram dentro da média anual, já nos anos seguintes até o ano de 2018, acima desse nível.



Figura 5: Número de artigos elaborados por ano.

Com relação às autorias dos artigos, a Tabela 2 evidencia a superioridade de publicações desenvolvidas em conjunto, com predomínio de quartetos, seguido por duplas e trios. Observa-se que poucos trabalhos foram desenvolvidos individualmente.

Tabela 2: Composição das autorias dos artigos desenvolvidos.

\begin{tabular}{lll}
\hline Autorias & no de artigos & Percentual \\
\hline 1 & 6 & $6,67 \%$ \\
2 & 20 & $22,22 \%$ \\
3 & 20 & $22,22 \%$ \\
4 & 29 & $32,23 \%$ \\
5 & 12 & $13,33 \%$ \\
6 & 3 & $3,33 \%$ \\
\hline
\end{tabular}

Do universo das 300 autorias distribuídas entre os 90 artigos selecionados, pode-se observar que são referentes a 288 autores distintos, onde grande maioria desses registraram apenas uma publicação e 
somente um autor publicou mais de 2 artigos no período. Portanto, fica evidenciada uma variedade de autores nas publicações, conforme se pode observar na Tabela 3.

Tabela 3: Artigos publicados por autores.

\begin{tabular}{lll}
\hline Artigos publicados & Autores & Percentual \\
\hline 1 & 280 & $97,22 \%$ \\
2 & 7 & $2,43 \%$ \\
6 & 1 & $0,35 \%$ \\
\hline
\end{tabular}

A Figura 6 exibe o percentual das 300 autorias distintas por gênero, evidenciando o predomínio do sexo feminino, que contempla 159 autorias no estudo. Em detrimento, o sexo masculino contempla 141 autorias.

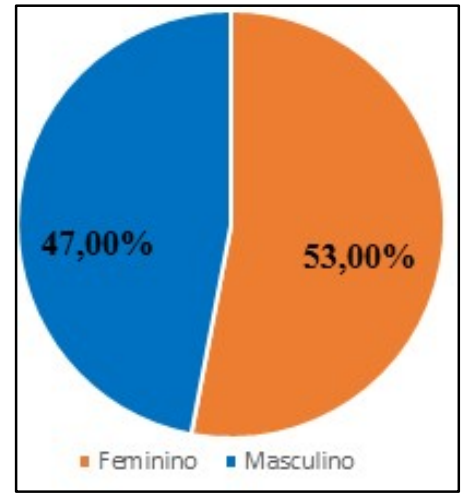

Figura 6: Percentual das autorias dos artigos distribuídas de acordo com o sexo.

No que tange à titulação das autorias dos artigos, a Tabela 4 evidencia a preponderância de doutores e mestres, onde somadas contemplam 62,00\% das autorias das publicações.

Tabela 4: Classificação da titulação das autorias dos artigos.

\begin{tabular}{lll}
\hline Escolaridade & Quantidade & Percentual \\
\hline Cursando Ensino médio & 3 & $1,00 \%$ \\
Acadêmico & 11 & $3,67 \%$ \\
Graduado & 16 & $5,33 \%$ \\
Pós-Graduando & 1 & $0,33 \%$ \\
Especialista & 2 & $0,67 \%$ \\
Mestre & 49 & $16,33 \%$ \\
Mestrando & 36 & $12,00 \%$ \\
Doutor & 137 & $45,67 \%$ \\
Doutorando & 38 & $12,67 \%$ \\
Pós-Doutorado & 7 & $2,33 \%$ \\
\hline
\end{tabular}

A Tabela 5 exibe os autores com maior número de publicações de artigos relacionados ao tema no período analisado, onde se destaca a doutora da Universidade Federal de Santa Catarina (UFSC) Elisete Dahmer Pfitsher. Ressalta-se que a pesquisadora também havia se destacado no estudo de Rohrich et al. (2019).

Quanto às instituições vinculadas às autorias, a Tabela 6 evidencia que 124 instituições distintas deram suporte às publicações, e que a UFSC é a instituição em maior evidência. Embora se constate essa superioridade, pode-se observar que não existe uma grande concentração nas publicações por uma única instituição, vide que 60 instituições diferentes compuseram a publicação de apenas um artigo cada no período analisado. 
Tabela 5: Classificação dos autores com maior número de publicações no período.

\begin{tabular}{ll}
\hline Autores & no de publicações \\
\hline PFITSCHER, Elisete Dahmer & 6 \\
AFONSO, Tarcísio & 2 \\
ESTIVALETE, Vania de Fátima Barros & 2 \\
LOCATELLI, Ronaldo Lamounier & 2 \\
MADRUGA, Lúcia Rejane da Rosa Gama & 2 \\
ROSA, Fabricia Silva da & 2 \\
TELOCKEN, Suelen Geíse & 2 \\
TREVISAN, Marcelo & 2 \\
\hline
\end{tabular}

Tabela 6: Classificação das Instituições com maior número de publicações no período.

\begin{tabular}{lll}
\hline Instituição & Quantidade de artigos & Percentual \\
\hline UFSC & 10 & $8,00 \%$ \\
UFSM & 8 & $6,40 \%$ \\
UNINOVE & 5 & $4,00 \%$ \\
USP & 5 & $4,00 \%$ \\
FPL & 3 & $2,40 \%$ \\
IFRN & 3 & $2,40 \%$ \\
UFMG & 3 & $2,40 \%$ \\
UFRJ & 3 & $2,40 \%$ \\
UFS & 3 & $2,40 \%$ \\
Escola Superior Dom Helder Câmara & 2 & $1,60 \%$ \\
PUC & 2 & $1,60 \%$ \\
UERJ & 2 & $1,60 \%$ \\
UFC & 2 & $1,60 \%$ \\
UFLA & 2 & $1,60 \%$ \\
UFMS & 2 & $1,60 \%$ \\
UFRN & 2 & $1,60 \%$ \\
UFV & 2 & $1,60 \%$ \\
UNAMA & 2 & $1,60 \%$ \\
UNB & 2 & $1,60 \%$ \\
UNIOESTE & 2 & $1,60 \%$ \\
Outras Instituições com apenas uma publicação & 60 & $48,00 \%$ \\
\hline
\end{tabular}

Na Tabela 7 é possível verificar quais foram as fontes de publicações com mais artigos publicados acerca do tema. Observa-se que os artigos selecionados foram publicados em 42 revistas distintas, onde a Revista de Gestão Ambiental e da Sustentabilidade obteve destaque com o maior número de publicações. Não obstante essa constatação se verifica a existência de uma grande quantidade de revistas (30), que contém em seu acervo apenas uma publicação no período da análise.

Tendo em vista que o Qualis-Periódicos é um instrumento de grande notoriedade de classificação e avaliação da produção científica, pode-se observar na Tabela 8 que prevaleceram as publicações de artigos em periódicos de Qualis B2, seguidos pelo Qualis B3, B1 e A2. Nota-se a ausência de publicações acerca do tema em periódicos de Qualis A1, o de classificação mais elevada. Também não foram realizadas publicações em periódicos de Qualis A3 e A4.

Tabela 7: Classificação da produção científica do período de acordo com periódicos.

\begin{tabular}{lll}
\hline Revista & Publicações & Percentual \\
\hline Revista de Gestão Ambiental e da Sustentabilidade & 17 & $18,89 \%$ \\
HOLOS & 9 & $10,00 \%$ \\
Revista de Administração Pública-RAP & 7 & $7,78 \%$ \\
Revista Gestão Universitária na América Latina & 6 & $6,67 \%$ \\
Revista Metropolitana de Sustentabilidade & 6 & $6,67 \%$ \\
Ambiente \& Sociedade & 3 & $3,33 \%$ \\
Acta Scientiarum. Biological Sciences & 2 & $2,22 \%$ \\
REAd: Revista Eletrônica de Administração & 2 & $2,22 \%$ \\
Revista Ambiente \& Água & 2 & $2,22 \%$ \\
\hline
\end{tabular}




\begin{tabular}{|c|c|c|}
\hline Revista Controle & 2 & $2,22 \%$ \\
\hline Revista de Direito e Sustentabilidade & 2 & $2,22 \%$ \\
\hline Revista Inovação, Projetos e Tecnologias & 2 & $2,22 \%$ \\
\hline Brazilian Journal of Development & 1 & $1,11 \%$ \\
\hline Conhecer: Debate entre o público e o privado & 1 & $1,11 \%$ \\
\hline Diálogo & 1 & $1,11 \%$ \\
\hline Enfoque: Reflexão Contábil & 1 & $1,11 \%$ \\
\hline Revista de Administração FACES Journal & 1 & $1,11 \%$ \\
\hline Interações (Campo Grande) & 1 & $1,11 \%$ \\
\hline Revista IPECEGE & 1 & $1,11 \%$ \\
\hline Meridiano 47 & 1 & $1,11 \%$ \\
\hline Política \& Sociedade & 1 & $1,11 \%$ \\
\hline REGE - Revista de Gestão & 1 & $1,11 \%$ \\
\hline Revista Brasileira de Enfermagem & 1 & $1,11 \%$ \\
\hline Revista Brasileira de Pós-graduação & 1 & $1,11 \%$ \\
\hline Revista CONFINS & 1 & $1,11 \%$ \\
\hline Revista de Administração Mackenzie & 1 & $1,11 \%$ \\
\hline Revista de Ciências da Administração & 1 & $1,11 \%$ \\
\hline Revista de Ciências Humanas & 1 & $1,11 \%$ \\
\hline Revista de Contabilidade e Controladoria (RC\&C) & 1 & $1,11 \%$ \\
\hline Revista de Direito Brasileira & 1 & $1,11 \%$ \\
\hline Revista de Gestão em Sistemas de Saúde & 1 & $1,11 \%$ \\
\hline Revista De Gestão, Finanças E Contabilidade & 1 & $1,11 \%$ \\
\hline Revista de Sociologia e Política & 1 & $1,11 \%$ \\
\hline Revista Digital de Biblioteconômica e Ciência da Informação & 1 & $1,11 \%$ \\
\hline Revista Eletrônica de Educação & 1 & $1,11 \%$ \\
\hline Revista Eletrônica de Estratégia e Negócios & 1 & $1,11 \%$ \\
\hline Revista ESMAT & 1 & $1,11 \%$ \\
\hline Revista Espaço Acadêmico & 1 & $1,11 \%$ \\
\hline REFAS - Revista Fatec Zona Sul & 1 & $1,11 \%$ \\
\hline Revista Gestão e Desenvolvimento & 1 & $1,11 \%$ \\
\hline Revista Internacional de Ciências & 1 & $1,11 \%$ \\
\hline Sociedade \& Natureza & 1 & $1,11 \%$ \\
\hline
\end{tabular}

Tabela 8: Classificação da produção científica do período de acordo com Qualis-Periódicos.

\begin{tabular}{lll}
\hline Qualis & $\mathbf{n o}$ de artigos & Percentual \\
\hline B2 & 38 & $42,22 \%$ \\
B3 & 23 & $25,56 \%$ \\
B1 & 13 & $14,44 \%$ \\
A2 & 7 & $7,78 \%$ \\
B4 & 4 & $4,44 \%$ \\
B5 & 1 & $1,11 \%$ \\
N/A & 4 & $4,44 \%$ \\
\hline
\end{tabular}

Considerando a importância exercida pela metodologia de pesquisa na elaboração dos trabalhos científicos, que consiste na direção e norteamento para o aprendizado do objeto ou fenômeno investigado, a Tabela 9 apresenta a caracterização da tipologia das pesquisas desenvolvidas quanto aos objetivos e abordagem, onde nota-se o predomínio de pesquisas descritivas e qualitativas.

Tabela 9: Classificação da produção científica do período de acordo com metodologia.

\begin{tabular}{llllll}
\hline Objetivos & No de artigos & Percentual & Abordagem & № de artigos & Percentual \\
\hline Descritiva & 48 & $53,33 \%$ & Qualitativa & 57 & $63,33 \%$ \\
Descritiva-Exploratória & 27 & $30,00 \%$ & Quantitativa & 18 & $20,00 \%$ \\
Exploratória & 10 & $11,11 \%$ & Quali-Quantitativa & 15 & $16,67 \%$ \\
Explicativa-Exploratória & 3 & $3,33 \%$ & & \\
Explicativa & 1 & $1,11 \%$ & & & \\
Descritiva-Explicativa & 1 & $1,11 \%$ & & & \\
\hline
\end{tabular}

No que se refere ao conteúdo dos artigos analisados, a Tabela 10 exibe a classificação de acordo com os temas tratados. 
Tabela 10: Classificação da produção científica do período de acordo com temas.

\begin{tabular}{lll}
\hline Tema & № de artigos & Percentual \\
\hline Avaliação e Desenvolvimento da Consciência Sustentável & 38 & $42,22 \%$ \\
Gestão de Resíduos e Coleta Seletiva & 15 & $16,67 \%$ \\
Compras Públicas Sustentáveis & 14 & $15,56 \%$ \\
Adesão a Programas de sustentabilidade & 10 & $11,11 \%$ \\
Eficiência Energética & 4 & $4,44 \%$ \\
Racionalização no uso da água & 4 & $4,44 \%$ \\
Racionalização no uso do papel & 2 & $2,22 \%$ \\
Construções Sustentáveis & 2 & $2,22 \%$ \\
Deslocamento de Pessoal & 1 & $1,11 \%$ \\
\hline
\end{tabular}

O tema Avaliação e Desenvolvimento da Consciência Sustentável foi o mais abordado, pois um elevado número de estudos procurou avaliar a consciência ambiental e determinar o nível de sustentabilidade exercido nas instituições públicas. Identifica-se a necessidade de um maior número de estudos a serem desenvolvidos sobre o tema deslocamento de pessoal, haja vista a necessidade de alternativas de locomoção mais sustentáveis.

\section{CONCLUSÕES}

A análise dos artigos selecionados permitiu atingir o objetivo proposto de analisar o desenvolvimento das pesquisas acerca da sustentabilidade no setor público brasileiro e nas instituições públicas de ensino superior, no período de Janeiro de 2010 a Setembro de 2019, nos periódicos nacionais, pois foi possível identificar as principais características desses estudos.

Foi constatado que sob a perspectiva do setor público, as instituições mais analisadas nos artigos foram as de ensino superior, sustentando participação na metade do portfólio bibliográfico selecionado. A tendência é que o ano de 2019 registre um número pequeno de publicações, abaixo da média anual de artigos publicados no período, mesmo levando em consideração que o levantamento foi realizado até 30 de Setembro.

O tema Avaliação e Desenvolvimento da Consciência Sustentável foi o mais abordado e os periódicos com maior número de publicações foram de Qualis B2, sendo a Revista de Gestão Ambiental e da Sustentabilidade a possuidora do maior acervo. Com relação ao perfil dos pesquisadores, foi verificada a preponderância do sexo feminino e da titulação de doutores. As parcerias em quartetos estão presentes em maior incidência nos artigos e grande parte dos autores publicou apenas um documento. A autora com maior número de publicações foi Elisete Dahmer Pfitsher e a Instituição com maior vínculo de autores foi a UFSC.

Os objetivos e abordagem metodológica em maior evidência foram a descritiva e qualitativa, respectivamente. Ressalta-se que a presente pesquisa apresenta uma limitação no tocante à seleção dos artigos analisados, pois foram considerados para triagem apenas os que integravam o acervo do Portal da Capes, durante o período de abrangência do estudo, e que puderam ser localizados com os termos pesquisados. Dessa forma, não se descarta a hipótese de que existam outros artigos que tratem sobre o tema.

Como proposta para estudos futuros sugere-se expandir essa análise realizada para a iniciativa privada e as instituições privadas de ensino superior, para que se possam apresentar as características do 
conhecimento cientifico acerca da sustentabilidade nessas instituições em comparativo com o setor público e as instituições públicas de ensino superior. Espera-se que o presente estudo possa contribuir para a compreensão do cenário atual do desenvolvimento de pesquisas científicas acerca da sustentabilidade no setor público e nas instituições públicas de ensino superior e que estimule o interesse e a concepção de novos estudos nesse sentido.

\section{REFERÊNCIAS}

BETIOL, L. S.; UEHARA, T. H. K.; LALOE, F. K.; APPUGLIESE, G. A.; ADEODATO, S.; RAMOS, L.; MONZONI NETO, M. P.. Compra sustentável: $A$ força do consumo público $\mathrm{e}$ empresarial para uma economia verde e inclusiva. São Paulo: Programa Gestão Pública e Cidadania, 2012.

BRASIL. Ministério do Meio Ambiente. A3P: Instituições parceiras com termo de adesão vigente. Brasília: MMA, 2019.

BRASIL. Ministério do Meio Ambiente. Cartilha A3P: Como implantar a A3P. 2 ed. Brasília: MMA, 2016.

BRASIL. Constituição da República Federativa do Brasil de 1988. Senado Federal. Brasília: DOU, 1988.

BRASIL. Decreto n. 7.746, de 5 de junho de 2012. Regulamenta o art. 3ㅇ da Lei no 8.666, de 21 de junho de 1993, para estabelecer critérios, práticas e diretrizes para a promoção do desenvolvimento nacional sustentável nas contratações realizadas pela administração pública federal, e institui a Comissão Interministerial de Sustentabilidade na Administração Pública - CISAP. Brasília: DOU, 2012.

BRASIL. Decreto n. 5.940, de 25 de Outubro de 2006. Institui a separação dos resíduos recicláveis descartados pelos órgãos e entidades da administração pública federal direta e indireta, na fonte geradora, e a sua destinação às associações e cooperativas dos catadores de materiais recicláveis, e dá outras providências. Brasília: DOU, 2006.

BRASIL. Secretaria de Logística e Tecnologia da Informação do Ministério do Planejamento, Orçamento e Gestão. Instrução Normativa n. 10, de 12 de novembro de 2012. Estabelece regras para elaboração dos Planos de Gestão de Logística Sustentável de que trata o art. 16, do Decreto no 7.746, de 5 de junho de 2012, e dá outras providências. Brasília: DOU, 2012.

CAMELO, G. L. P.; MONTEIRO, M. O.. Agenda Ambiental na Administração: A3P nos campi do IFRN: Um olhar a partir dos gestores. EmpíricaBR: Revista Brasileira de Gestão, Negócio e Tecnologia da Informação, v.1, n.1, p.26-42, 2015. DOI: https://doi.org/10.15628/empiricabr.2015.3338

CAVAlCANTE, M. L. S. A.. Administração Pública e Agenda Ambiental: A3P. Considerações sobre a implementação nos órgãos públicos. Revista Controle Doutrina e Artigos, v.10, p.193-216, 2012. DOI: https://doi.org/10.32586/rcda.v10i1.183

CHAVES, L. C.; FREITAS, C. L.; ENSSLIN, L.; PFITSCHER, E. D. Gestão ambiental e sustentabilidade em instituições de ensino superior: construção de conhecimento sobre o tema. Revista Gestão Universitária na América Latina -
GUAL, v.6, n.2, p.33-55, 2013. DOI:

http://dx.doi.org/10.5007/1983-4535.2013v6n2p33

CHELALA, C.. Economia verde: desafios para o setor público. Planeta Amazônia: Revista Internacional de Direito Ambiental e Políticas Públicas, Macapá, v.4, p.45-59, 2012.

FARIAS FILHO, M. C.; ARRUDA FILHO, E. J. M.. Planejamento da pesquisa científica. 2 ed. São Paulo: Atlas, 2015.

INEP. Censo da Educação Superior 2018: notas estatísticas. Brasília: INEP, 2019.

HENCHEN, A. V.; MOURA-LEITE, R.; LOPES, J. C.. Sustentabilidade e Gestão de Instituições de Ensino Superior: Análise da Produção Científica. Revista de Gestão Ambiental e Sustentabilidade, v.8, n.1, p.38-60, 2019. DOI: https://doi.org/10.5585/geas.v8i1.13763

MPOG. Ministério do Planejamento, Orçamento e Gestão. Portaria Interministerial n. 244, de 6 de junho de 2012. Institui o Projeto Esplanada Sustentável - PES, cuja finalidade é integrar ações que visam à melhoria da eficiência no uso racional dos recursos públicos e à inserção da variável socioambiental no ambiente de trabalho. Brasília: DOU, 2012.

ONU. Organização das Nações Unidas. Transformando Nosso Mundo: A Agenda 2030 para o Desenvolvimento Sustentável. Rio de Janeiro: UNIC RIO, 2015.

PINSKY, V. C.; GOMES, C. M.; KRUGLIANSKAS, I.. Metas brasileiras no Acordo de Paris: reflexões sobre o papel das universidades. Revista de Gestão Ambiental e Sustentabilidade, v.8, n.2, p.335-362, 2019. DOI: https://doi.org/10.5585/geas.v8i2.11229

ROCHA, S. M.; ROCHA, R. R. C.; BIAZOTTO, P. D.; LEITE, A. H. O.. Sustentabilidade na Administração Pública. Revista ESMAT, v.8, n.11, p.105-120, 2016. DOI: https://doi.org/10.34060/reesmat.v8i11.125

ROHRICH, S. S.; TAKAHASHI, A. R. W.. Sustentabilidade ambiental em Instituições de Ensino Superior, um estudo bibliométrico sobre as publicações nacionais. Gestão \& Produção, São Carlos, v.26, n.2, 2019. DOI: https://doi.org/10.1590/0104-530X2861-19

ROOS, A.; BECKER, E. L. S.. Educação ambiental e Sustentabilidade. Revista Eletrônica em Gestão, Educação e Tecnologia Ambiental, v.5, p.857-866, 2012. DOI: http://dx.doi.org/10.5902/223611704259

RUBBO, P.; PILATTI, L. A.; TELLES, L. B.; BITTENCOURT, J. V. M.; FRANCISCO, A. C.. Sustentabilidade organizacional: Uma 
análise da produção científica da base Scopus no período de 2005 a 2014. Revista Espacios, v.37, n.13, 2016.

SANTOS, F. R.. As universidades e a sustentabilidade ambiental. Revista Gestão Universitária, v.10, p.1-17, 2018.

SDSN. Australia/Pacific. Getting started with the SDGs in universities: A guide for universities, higher education institutions, and the academic sector. Australia, New Zealand and Pacific Edition. Sustainable Development Solutions Network - Australia/Pacific. Melbourne: SDSN 2017.

TCU. Tribunal de Contas da União. Sustentabilidade na Administração Pública Federal. Brasília: TCU, 2017.

A CBPC - Companhia Brasileira de Produção Científica (CNPJ: 11.221.422/0001-03) detém os direitos materiais desta publicação. Os direitos referem-se à publicação do trabalho em qualquer parte do mundo, incluindo os direitos às renovações, expansões e disseminações da contribuição, bem como outros direitos subsidiários. Todos os trabalhos publicados eletronicamente poderão posteriormente ser publicados em coletâneas impressas sob coordenação da Sustenere Publishing, da Companhia Brasileira de Produção Científica e seus parceiros autorizados. Os (as) autores (as) preservam os direitos autorais, mas não têm permissão para a publicação da contribuição em outro meio, impresso ou digital, em português ou em tradução. 